\title{
Suggestions on Development Strategies and Policies of National Parks in Qinzhou Under Strategy of "One Belt and One Road"
}

\author{
Gui-yuan HUANG ${ }^{11}$
}

(School of Economics and Management, Qinzhou University, Qinzhou, Guangxi, China,535099)

Key Words: One Belt and One Road; Qinzhou; two parks and one area; industrial economy

\begin{abstract}
Guangxi Province is an enthusiastic supporter of the initiative on building the $21^{\text {st }}$ Century Maritime Silk Road. One of its city, Qinzhou, with the knowledge of its strategic backgrounds, expects to seize every possible chance to take an active part in the initiative of "One Belt and One Road". With this goal, Qinzhou endeavors to put forward relevant policy suggestions on the development of its national industrial parks in different aspects, such as investment and trade facilitation, cross-border financial cooperation and reform of management system, so as to enhance itself to further participate in the construction of "One Belt and One Road”.
\end{abstract}

Qinzhou, Guangxi, is an international channel in ASEAN that helps establish new strategic pivots in the opening-up progression of south-central and southwest regions. With the knowledge of strategic backgrounds and orientations of industrial developments, as well as the current situations, problems, opportunities and challenges its national industrial parks are faced with, the city should bring into full play the optimizing and regulating impacts of national parks on its overall industrial developments, so as to actively participate the initiative of "One Belt and One Road", which has become a major concern of governments. Therefore,

\footnotetext{
${ }^{1}$ Introduction of Author: Huang Guiyuan (1982.8 - ), female, Han Nationality, born in Qinzhou, Guangxi, Master's Degree, associate professor in School of Economics and Management, Qinzhou University, specialized in researches on logistics strategy.

Foundation Items: a project supported by National Social Science Foundation---"On Mechanism of China- ASEAN Maritime Inter-Connectivity" (item number: 14XGJ004); a major project in Beibu Gulf Culture Research Center---"On Historical Basis and Practical Strategy of Guangxi Participating in Construction of the $21^{\text {st }}$ Century Maritime Silk Road"; support from Beibu Gulf Port Logistics Laboratory (a key laboratory in high education institutions in Guangxi) Address: No. 125 North Wenfeng Road, Qinzhou, Guangzhou. Zip code: 535099. Phone:
} 13877758042 Email: huangguiyuan2010@126.com 
the paper tries to come up with multiple policy suggestions on national parks in Qinzhou from different perspectives, such as investment and trade facilitation, cross-border financial cooperation and reform of management system, with the aim of facilitating high-end and modern service industry and advanced manufacturing industry in Qinzhou to develop services in cluster, including the industries of shipping logistics, international trade, equipment manufacturing, information service, cross-border finance and high technology.

\section{Policy on Investment and Trade Facilitation}

The implementation of "One Belt and One Road" strategy provides new opportunities and developmental potentials for countries and regions along the belt and road. Guangxi, a province in China that is connected to ASEAN countries both in marine and terrestrial ways, is also an outlet of the $21^{\text {st }}$ Century Maritime Silk Road. Besides, the province has also established close trade relationships with ASEAN countries. Though endowed with the natural advantages, Guangxi is also faced with multiple problems related to investment and trade facilitation, such as poor customs clearance, slow transportation and logistics, and trade barriers. Qinzhou is located in the front line and regarded as a miniature of the business relations between Guangxi and ASEAN. Similarly, Qinzhou is also troubled with the above problems. If to share the benefits of "One Belt and One Road” project, Guangxi Zhuang Autonomous Region and Qinzhou should continue increasing software and hardware investments on their own national industrial parks, as specified below.

\section{To Deepen Reform of Port Management System and Strengthen}

\section{Cooperation on Regional Clearance Integration}

Firstly, it is necessary to constantly enhance the communications and cooperation between customs of ASEAN countries and national parks in Qinzhou, including China-Malaysia Qinzhou Industrial Park, Guangxi Qinzhou Free Trade Port Area and State-Level Qinzhou Harbor Economic and Technical Development Zone (especially for Guangxi Qinzhou Free Trade Port Area). Also, information sharing should be guaranteed. Dependent on Qinzhou Electronic Port, a port public information platform can be constructed which is trans-departmental, trans-industrial and trans-regional. The platform simultaneously integrates functions of e-government, e-commerce and e-logistics, and will serve as a Sino-ASEAN port logistics information platform. Moreover, the platform can smoothly provide information flows, document flows, cargo flows and capital flows of cargoes imported into and exported from different ports. Based on this, Qinzhou can be interconnected with ASEAN ports. Secondly, through negotiations, communications and exchanges, the entry and exit procedures implemented in national parks in Qinzhou and ASEAN countries can be gradually simplified, which can facilitate the smooth circulation of personnel and cargoes. Last but not the least, clearance integration of Qinzhou with other cities in Guangxi, as well as Hainan, Guangdong and Fujian should be achieved, so as to realize "one-off declaration, one-off inspection and one-off release”. In addition, a pilot for China-Malaysia clearance integration can be built up and "two countries-one inspection" can be achieved.

\section{To Improve Construction of Infrastructure and Promote Software and Hardware Investment Environment}

To become an international channel connected to ASEAN countries, a center that develops strategic pivots in southwest and south-central regions, and a gateway organically liked to "One Belt and One Road", Qinzhou should pay great emphasis on the functions of 
national parks. Through the platform of national parks, Qinzhou can attract foreign and domestic investments, especially investments from ASEAN countries. Based on this, industrial agglomeration effect can be created and the whole industries in Qinzhou can be regulated and optimized. Therefore, it is extremely important to strengthen the construction of infrastructures in national parks and improve the software and hardware investment environment.

Of all the national parks in Qinzhou, State-Level Qinzhou Harbor Economic and Technical Development Zone, for its long-standing existence, is endowed with remarkable developments in terms of infrastructures, such as dock, shipping lines and schedules, number of berths, annual synthetic handling capacity and cargo throughput. Whereas, China-Malaysia Qinzhou Industrial Park and Guangxi Qinzhou Free Trade Port Area are relatively weak in the construction of infrastructures, due to their behindhand development, the former of which has more serious conditions in this matter. We find that China-Malaysia Qinzhou Industrial Park has not yet constructed facilities supporting urban functions and its completed infrastructures and auxiliary facilities only accounts for 30 to 40 percent of its planned volumes. Therefore, it to a great extent hinders investments on it. Meanwhile, since national parks in Qinzhou are all far away from the city center, it is hard for them to enjoy the convenience of the traffic network system in the city center. Therefore, it is a must to constantly construct public facilities, such as transportation, education, health-care and entertainment facilities. Besides, it is also important to strengthen the construction of civic facilities, including water supply and drainage, power, gas and communication engineering facilities, providing fundamental guarantee for development planning of national parks in Qinzhou.

On the basis of improving infrastructures, it is important to improve software investment environment, which requires national parks in Qinzhou to enforce the informatization construction. To meet the goal, we should facilitate the construction of China-ASEAN Port Logistics Information Center and continue spreading the service philosophy of "Internet+". Then, we should improve the processing and passing of information in China-Malaysia Qinzhou Industrial Park, Guangxi Qinzhou Free Trade Port Area and State-Level Qinzhou Harbor Economic and Technical Development Zone, and establish a complete and efficient logistics chain which can provide real-time, high-efficiency and reliable information sources for interested parties, including clients and enterprises. On this basis, the port logistics system can be improved. Moreover, we should make great efforts to introduce large shipping companies, such as China Shipping (Group) Company and China Ocean Shipping (Group) Company, with the aim of developing new shipping lines for ports in coastal cities in China and other ASEAN countries.

\section{To Implement Preferential Policy for Investments and Create Investment Facilitating Conditions}

China-Malaysia Qinzhou Industrial Park, Guangxi Qinzhou Free Trade Port Area and State-Level Qinzhou Harbor Economic and Technical Development Zone are granted with not only preferential policies for investments on national parks but also other preferential policies enacted by West Development, Guangxi Beibu Gulf Economic Zone and Qinzhou City. Hence, we need to promote and disseminate, on a nationwide basis, the advantages and chances that national parks in Qinzhou are facing, as well as preferential taxation policies; besides, we ought to strengthen the global investment awareness and efforts and implement the "going 
out" strategy, so as to attract more domestic and foreign enterprises (including those in ASEAN countries) to move into national parks in Qinzhou and make investments on production. Furthermore, it is important to strengthen supports for enterprises settled in the parks in terms of land, tax and finance and personnel. For those enterprises, preferential policies on import and export duties are granted; some cargoes sold in the parks can enjoy duty-free policies; export profit, give identity; more enterprises should have the opportunity to have their income tax, value-added tax and tax reduced and the period of tax relief should be elongated; the taxes of investments on fixed assets in the national parks, such as workshop and equipment, should be levied according to the credit of taxable in proportion to fixed assets; for expenses of research and development and personnel training, the taxes should be levied according to the credit of taxable in proportion to investments. In addition, with adherence to national taxation policies, Guangxi Zhuang Autonomous Region should consider its actual conditions and enact more laws, regulations and normative documents which can determine the boundaries and scope of preferential policies and specifically define the contents of preferential policies. Therefore, enterprises and companies that move into the industrial parks are granted with more specific preferential policies, so it supports the development of national industrial parks in Qinzhou City, and beverages the development of all industries in the city.

\section{Policy on Cross-Border Financial Cooperation}

Industrial developments are inseparable from financial supports. The case also applied to the developments of national parks and industries in Qinzhou. Through investigations and reference to relevant documents, we find that though our country, Guangxi Zhuang Autonomous Region and Qinzhou City have enacted policies on financial support for the enterprises in industrial parks in Qinzhou, the policies are not sufficiently implemented. By now, there are still many problems. For instance, the management committee cannot promote financial services with all its strength; banks are weak in credits; financial services are not innovative enough; cooperation among regions is insufficient; and regional financial cooperation platform is in a great demand. Therefore, the industrial parks and enterprises in Qinzhou still carry out the financial service model of "independent bank financing”, which greatly stops the developments of industrial parks and industries in the city.

\section{To Develop Financing and Leasing Businesses and Create a Financing and Leasing Highland Oriented to ASEAN Countries}

National parks in Qinzhou, especially for Guangxi Qinzhou Free Trade Port Area and State-Level Qinzhou Harbor Economic and Technical Development Zone, should seize all precious opportunities to develop China-ASEAN cooperation, open up Beibu Gulf area and build up Beibu Gulf Free Trade Area. Referring to the experiences of China (Shanghai) Pilot Free Trade Zone and Dongjiang Free Trade Port Zone of Tianjin, we should focus on financing and leasing businesses and create a financing and leasing highland that is oriented to ASEAN countries. We should also set up a team to promote the financing and leasing transaction platform; the team is led by the municipal government and consists of multiple departments, including Department of Commerce, Banking Board, Finance Office, Industrial and Commercial Administration (in charge of registering the ownership of financed and leased properties) and Management Committee of Guangxi Qinzhou Free Trade Port Area. Besides, we should strengthen the supports for policies on financing and leasing, try to 
remove the political barriers that hinder the development of financing and leasing industry, consolidate the institutional foundation of industrial developments, and ensure the smooth development of financing and leasing businesses by laws. Moreover, we should also rely on platforms, such as Guangxi Qinzhou Free Trade Port Area, to further study political pivots that integrate multiple innovative functions, such as offshore accounts by residents and centralized management of foreign debts and to create a comprehensive environment beneficial to the clustering of financing and leasing enterprises. Apart from this, we should strive for the construction of an electronic database for trading platforms which should focus on gathering information related to financing and leasing demands, and then enter the data of potential leasing demands into the database. So the database can bring plenty of clients for leasers and gradually exerts a scale effect to reduce rentals and increase leasing demands. On this basis, it can further expand financing and leasing markets. In addition, we should also make more efforts to promote the concept of financing and leasing, and create a social environment that advocates the usage of financing and leasing transaction platforms. Last but not least, we can cooperate high education institutions (such as Qinzhou University) and social education organizations to offer specified financing and leasing courses and various seminars, with the aim of cultivating financing and leasing specialists and set financing and leasing qualification training and assessment as a part of services provided by transaction platforms.

To Increase Cross-Border Cooperation on Financial Infrastructure and Establish a Financial Reform Risk-Aversion Mechanism

As our country is developing close contacts with ASEAN countries in the aspect of trade and cultural tourism, cross-border financial cooperation has become an essential part of the communications between counties at present and in the future. Guangxi, an edgewise and coastal region in China, ought to accelerate the construction of testing area for comprehensive edgewise financial reform, and promote the opening-up and development of edgewise regions. Therefore, Guangxi Zhuang Autonomous Region should actively seize the strategic opportunities of "One Belt and One Road". With the leading impact of China-Malaysia Qinzhou Industrial Park, Guangxi Qinzhou Free Trade Port Area and State-Level Qinzhou Harbor Economic and Technical Development Zone, cross-border cooperation on financial infrastructures in China and other ASEAN countries should be promoted. Specifically, we should cooperate to conduct cross-border credit checking, manage cross-border payment and settlement, construct a cross-border financial information station, develop a cross-border retail payment platform that is orientated towards ASEAN and Southern Asian countries, and explore the feasibility of clearing specific edgewise and cross-border currencies. Meanwhile, with the deepening of financial internationalization, financial markets are more open to foreign investments. While offshore financial centers are faced with more uncertainties and risks under new economic situations, cross-border industry regulation and collaboration are of increasingly greater importance. On the other hand, apart from cross-border cooperation on financial infrastructure, national parks in Qinzhou should also develop a complete mechanism that evades the risks of financial reform, and improve the supervision and prevention against risks of cross-border financial cooperation. For example, China-Malaysia Qinzhou Industrial Park and Guangxi Qinzhou Free Trade Port Area should collaborate with ASEAN countries to create an assessment mechanism of cross-border cash flow, improve the early-warning 
mechanism that inspects cross-border cash flows, exchange rates, debts and repayment capability, step up monitoring and controlling of cross-border financial crimes, and enhance the creation of financial ecologic environment.

\section{To Propel Innovations of Cross-Border Financial Businesses and Complete Cross-Border Financial Cooperation Mechanism}

Cross-border financial cooperation is an important means to create mutual benefits for both China and other ASEAN countries, as well as an essential part of financial reform that is implemented in edgewise regions, such as Guangxi and Yunnan. The focus of cross-border financial cooperation lies in the innovation of financial businesses and creation of financial cooperation mechanism. Therefore, we should actively promote Qinzhou and its industrial parks to work with ASEAN countries to innovate financial businesses and develop the business of cross-border and two-way RMB loaning, so as to facilitate the cross-border settlement of RMB, licensed RMB exchange, entry-exit administration of RMB in cash, listing trade of currencies and overseas investment of RMB on goods. Besides, the cooperation can also assist to construct pilot areas for testing the cross-border clearing and settlement of RMB with neighboring countries. Then we can try to make the pilots authorized as a centralized pilot which comprehensively operates and manages foreign exchange funds from transnational corporations, and establish a RMB settlement platform targeted at cross-border transactions..

\section{Policy on Management System Reform}

Currently industrial parks in Qinzhou have achieved some development. However, they are also faced with many problems. For example, from the perspective of self-development, the industrial parks are troubled with capital shortage which hinders the progression of project construction, insufficient flexibility of management systems, shortage of talents in organizations. On the other hand, from the perspective of external conditions, the industrial parks are faced with situations where top-level planning is in sufficient and parks are constrained when applying to the governmental support for funds, taxation policies and land policies. If Qinzhou is intended to actively fit in “One Belt and One Road” strategy, it should not only make political breakthroughs in investment and trade facilitation, cross-border financial cooperation and international industry cooperation, but also reform its management system whose reform should be focused on innovations and construction of pilots. Through the reform of management system, we can increase the internal power and improve core competence, so as to adjust to the strategic opportunities the industries in Qinzhou are faced with.

\section{To Innovate Management System and Improve Operational Mechanism}

Firstly, we should implement an enterprise-oriented park development mechanism. With the introduction of corporate development model, we can apply a new approach to develop and construct enterprises which is centered on market operation. For The establishment of the operation mechanism of the combination of government promotion and market operation. For China-Malaysia Qinzhou Industrial Park, a joint venture of China and Malaysia can be set up for the park development, construction, operation. Secondly, we should innovate park management approaches. Specifically, we should take active actions to equip the park with one-level finance, and have the park authorized with a provincial-level right to administrative examination and approval. Thirdly, we should establish a national, autonomous-regional and 
municipal government coordination mechanism, through which three levels of governments can work together to coordinate and guide the construction of park. Besides, we need to actively promote the establishment of a coordinating mechanism for the coordination with ASEAN countries, so that various preferential policies can be enforced and different disputes can be solved. Fourthly, we can establish a city-park integration mechanism in which the city and park's developments are linked together,. in order to fully mobilize Qinzhou to participated in constructing parks. With a close contact with locals, we can promote the rapid and harmonious development of the city and park, as well as coordinate the development in different aspects, such as planning integration, taxation integration, investment integration, major infrastructure construction integration, integration of land expropriation, demolition, reserve and transfer, integration of social service management, statistics integration and integration of main cadres management. Fifthly, we should innovate the government management mechanism. To be specific, we should actively promote the "flat" management mode, to develop a new mechanism which consists of government guidance, association's roe in promoting, and enterprises' role as a main body. The park is responsible for introducing projects and exploit land resources. The local management practices should be resigned to the local administrative division. Sixth is to innovate the public service mechanism. Service windows should be set up in the park and we should continue to strengthen essential public services provided for farmers and migrant workers, such as services of employment, health, medical care and schooling of children, so that they share the benefits of industrialization process and simultaneously get involved in the park. In addition, we should actively explore new business models, develop Entrusted Investment Management Approach, and work had to attract investments through thematic promotion, commissioned investment and point-to -point investment.

\section{To Improve Talent Introduction Mechanism and Create Talent Highland}

Economic growth is inseparable from the support of talents. However, one of the major problems that national parks in Qinzhou are faced with is the shortage of talents, specifically, not only talents in the filed of ports and logistics but also talents in other aspects. Therefore, with the consideration of characteristics of industrial development in Qinzhou, a long-term talent training project is the key to increase the core competitiveness of industrial parks. For port logistics, Qinzhou can draw some experiences on PSA of Singapore to introduce internationally renowned logistics enterprises, work with Qinzhou University to establish a logistics specialist training base, and emphasize the cultivation of logistics management talents who are also proficient in a foreign language and specialized in international businesses. In the meantime, we should also make plans to absorb high-competence talents all over the country or world, and create incentives to encourage and support large and qualified logistics enterprises to establish a research center of logistics engineering technologies. In other words, researches on and application of logistics information technologies and automation equipment should be emphasized. In addition, we should found special funds for talent training, and constantly absorb and cultivate top specialists with international outlooks.

\section{Conclusion}

Therefore, the policy of investment and trade facilitation, cross-border financial cooperation and reform of management system, can speed up the integration of Qinzhou One Belt and One Road development.with the aim of facilitating high-end and modern service 
industry and advanced manufacturing industry in Qinzhou to develop services in cluster, including the industries of shipping logistics, international trade, equipment manufacturing, information service, cross-border finance and high technology.

\section{References:}

[1] Zhang Chenglong \& Mai Fumin, Innovation of Financial Service Model of State-Level Qinzhou Harbor Economic and Technical Development Zone[J]. Business, 2015(6):165.In Chinese.

[2] Li Guanggui, Park Construction Under “One Belt and One Road” Strategy[J]. China Economic \& Trade Herald, 2015(20):24-25.

[3] Qiao Wei \& Yun Xia. Reflection on Constructing Competitive Industrial Parks Outside Sichuan Under“One Belt and One Road” Strategy[J]. Contemporary Economics, 2016(15):17-18.In Chinese.

[4] Zhang Yiyue. On Construction of China-Kazakhstan Lianyungang Logistics Park and Coordinated Development of Sino-Kazak International Trade[J]. Logistics Technology, 2015, 34(22):52-54.In Chinese.

[5] Li Dongjie, Regional Studies and the Cultural Rise Strategy of the "One Belt and One Road” Developmental Concept[J]. Academics, 2015(8):262-266

[6] Niles Hansen.Border Regions:A Critique of Spatial Theory and a European Case Study[J]. The Annals of Regional Science, 2012,111):3-4.

[7]Zeng,D.Z,Zhao L.Globalization, Interregional and International Inequalities[J]. Journal of Urban Economics, 2010,67(3):352-361.In Chinese.

[8] LIU QiangCAO Chaowen. Integrating Green Tourism of Jiangxi Province into "One Belt and One Road” Strategy[J]. Journal of Landscape Research 2015, 6(22):99-101.

[9] Dai Xiang, Technological Content of the Import of Services and the Transformation of Growth Patterns of China's Industrial Economy[J]. China Economist, 2014(2):58-74.In Chinese.

[10] Jun HuWu Xie, The Research on Situation and Prediction of Anqing's Industrial Economy[J]. International Conference on Humanities and Social Science Research 2015(09):68-75. 